\title{
UPAYA IBU HAMIL DALAM MENCEGAH BAYI BERAT LAHIR RENDAH DI WILAYAH UPTD KESEHATAN KECAMATAN SUKOREJO
}

\section{The Effort of Pregnant Mother in Preventing Low Birth Weigh in Sukorejo Perifer Hospital}

\author{
Sunarti ${ }^{1}$,Azizah Batrisya ${ }^{2}$
}

1. Staf Pengajar D3 Keperawatan Blitar (Poltekes Kemenkes Malang; s.kepsunarti@yahoo.co.id)

2 Mahasiswa D3 Keperawatan Blitar (Poltekes Kemenkes Malang)

\begin{abstract}
ABSTRAK
Latar Belakang Salah satu faktor yang memengaruhi risiko kematian bayi adalah bayi dengan berat lahir rendah. Oleh karena itu, upaya pemeliharaan kesehatan kehamilan harus lebih diperhatikan guna mempersiapkan generasi yang sehat dan menurunkan angka kematian bayi.

Tujuan: Tujuan penelitian ini untuk menggambarkan tentang upaya ibu hamil dalam mencegah terjadinya BBLR.

Metode: Setting studi kasus penelitian ini menggunakan deskriptif. Partisipan yang diambil sebanyak 15 ibu hamil. Pengumpulan data menggunakan kuisioner sejumlah 15 soal. Waktu pengambilan data dilakukan tanggal 10 April - 2 Mei 2019. Tempat penelitian di UPTD Kesehatan Kecamatan Sukorejo Kota Blitar.

Hasil peneltian meggambarkan upaya ibu hamil dalam mencegah BBLR dikategorikan baik dengan prosentase sebesar $73,3 \%$ dan $26,7 \%$ dalam kategori cukup.

Kesimpulan Gambaran upaya ibu hamil dalam mencegah BBLR katagiori baik dan upaya ibu dalam memanfaatan pelayanan kesehatn dan mengikuti penyuluhan kesehatanyang yang diadakan di tempat pelayanan kesehatan sangat kurang ( $7 \%$ ),yang tidak mengukuti penyuluhan dengan alasan tidak punya waktu ( $87 \%)$.
\end{abstract}

Kata kunci: Upaya, Ibu Hamil, BBLR

\section{ABSTRACK}

Backgraund: One of the factors that influence the risk of infant mortality is a baby with low birth weight. Therefore, health care efforts for pregnancy should be considered to prepare healthy generations and reduce infant mortality.

Aim : The purpose of this study is to describe the efforts of pregnant women to prevent LBW. This research use descriptive case studies me.

Method: Participants were taken as many as 15 pregnant women. Collecting data using questionnaires 15 questions. The time of data collection is carried out on 10 April - 2 May 2019. Place of research at Puskesmas Sukorejo.

Results: The results of the study describe the efforts of pregnant women in preventing $L B W$ in a good category with a percentage of $73.3 \%$ and $26.7 \%$ in the adequate category.

Conclusion :It is hoped that through this study pregnant women can realize the importance of maintaining pregnancy health to prevent $L B W$ and all relevant agencies can help improve the health of pregnant women by holding various counseling or activities to prevent $L B W$.

Keyword : Attemps, Pregnant Women, LBW 


\section{PENDAHULUAN}

Upaya pemeliharaan kesehatan bagi bayi dan anak harus lebih diperhatikan guna mempersiapkan generasi yang sehat dan berkualitas serta menurunkan angka kematian bayi dan anak. Salah satu faktor yang memengaruhi resiko kematian bayi adalah bayi dengan berat lahir rendah (BBLR). Oleh karena itu upaya yang dapat dilakukan untuk mencegah terjadinya kematian bayi adalah penanganan BBLR .

Bayi Berat Badan Lahir Rendah (BBLR) adalah bayi baru lahir dengan berat badan saat lahir kurang dari 2500 gram (sampai dengan 2499 gram). Sejak tahun 1961 WHO telah mengganti istilah premature dengan istilah BBLR. Hal ini dikarenakan tidak semua bayi yang lahir dengan berat kurang dari 2500 gram pada waktu lahir bayi premature (Yeyeh Ai, 2012). Bayi yang terlahir dengan BBLR memiliki resiko kematian 35 kali lebih tinggi dibandingkan dengan bayi yang lahir dengan berat badan diatas 2500 gram. Bayi dengan berat badan lahir rendah perlu diberikan perhatian khusus karena dapat menimbulkan permasalahan bahkan dapat menyebabkan kematian, sehingga akan berpengaruh kepada derajat kesehatan masyarakat.

Persentase BBLR di Indonesia pada tahun 2013 (10,2\%) lebih rendah dari tahun 2010 $(11,1 \%)$. Persentase BBLR terendah terdapat di provinsi Sumatera Utara $(7,2 \%)$ sedangkan persentase tertinggi terdapat di provinsi Sulawesi Tenggara (16,9\%). Persentase BBLR di perdesaan $(11,2 \%)$ lebih tinggi daripada di perkotaan (9,4\%) (Riskesdas dalam Irham, 2014). Menurut Survei Demografi dan Kesehatan (SDKI) tahun 2015 di Indonesia terdapat 7,5\% atau 355.000 bayi lahir dengan berat badan lahir rendah (Depkes RI, 2015).

Menurut data dari Badan Pusat Statistik Kota Blitar pada tahun 2016, jumlah bayi lahir dengan bayi berat lahir rendah sekitar 112 per 2117 kelahiran hidup (5,3\%). Dengan data per kecamatan sebagai berikut, Sukorejo 38 bayi lahir dengan berat lahir rendah dari 678 kelahiran hidup (5,6\%), Kepanjenkidul 30 bayi lahir dengan berat lahir rendah dari 631 kelahiran hidup (4,7\%), dan di kecamatan Sananwetan 44 bayi lahir dengan berat lahir rendah dari 808 kelahiran hidup (5,4\%) (Badan Pusat Statistik Kota Blitar, 2016). Sedangkan pada tahun 2017 tercatat ada 100 kasus kelahiran bayi dengan berat lahir rendah (Dinas Kesehatan Kota Blitar, 2018) 
Upaya pencegahan yang baik dapat menurunkan angka kelahiran bayi BBLR, hendaknya dilakukan secara komprehensif meliputi aspek promotif, preventif, kuratif, dan rehabilitatif secara terpadu. Namun lebih menekankan pada pencegahan primer yaitu promotif dan preventif. Upaya promotif dapat dilakukan dengan penyuluhan atau memberikan informasi kepada ibu hamil tentang kesehatan pada masa kehamilan untuk meningkatkan pengetahuan dan kesehatan ibu hamil. Upaya preventif dilakukan untuk mencegah penyakit, dengan melakukan imunisasi, mencukupi asupan gizi, mengonsumsi tablet Fe pada ibu hamil agar terhindar dari anemia, dan pemeriksaan rutin secara berkala (Ante Natal Care) sesuai dengan Permenkes No. 97 pasal 13 ayat 1 tentang Pelayanan Kesehatan Kehamilan yang mengharuskan ibu hamil melakukan pemeriksaan rutin minimal sebanyak empat kali yaitu satu kali pada trimester I, satu kali pada trimester II, dan dua kali pada trimester III.

Salah satu permasalahan yang banyak terjadi di masyarakat tentang ketidakpatuhan ibu hamil dalam mengkonsumsi tablet Fe hingga menyebabkan anemia. Padahal anemia merupakan penyebab tertinggi terjadinya kelahiran BBLR. Berdasarkan penelitian yang dilakukan oleh Ismi Trihardiani pada tahun 2011 menyatakan bahwa seluruh subyek yang melahirkan bayi dengan berat lahir rendah menderita anemia (100\%). Dari hasil studi pendahuluan yang dilakukan peneliti pada tanggal 13 Februari 2019 di UPTD Kesehatan Kecamatan Sukorejo didapatkan empat dari sepuluh ibu hamil yang menderita anemia mengaku tidak rutin mengkonsumsi tablet Fe dengan alasan tablet Fe memberikan efek mual dan muntah sehingga klien malas untuk mengkonsumsi secara rutin, selain itu beberapa klien mengatakan tidak rutin mengkonsumsi dengan alasan lupa.

Berdasarkan latar belakang tersebut peneliti ingin menggambarkan tentang upaya yang dapat dilakukan ibu hamil dalam mencegah BBLR pada saat kehamilan.

\section{METODE}

Penelitian ini menggunakan studi kasus dengan pendekatan deskriptif tentang upaya ibu hamil dalam mencegah bayi berat lahir rendah di wilayah UPTD Kesehatan Kecamatan Sukorejo. Pada studi kasus partisipan yang diambil sebanyak 15 ibu hamil yang memeriksakan kehamilan di Puskesmas Sukorejo dan bersedia menandatangani informed consent. Pengumpulan data bertempat di Puskesmas Sukoreio nada tanggal 10 April- 02 Mei 2019.

Keterangan :

$\mathrm{P}=$ Prosentase,

69 Copyright $@$ C 2019, JKM, p f= Jumlah jawaban yang diberikan, $\mathrm{n}=$ Jumlah skor. 
Teknik pengumpulan data menggunakan kuisoner yang berisi 15 soal. Analisa studi kasus ini menggunakan rumus:

$$
\mathrm{P}=\frac{f}{n} \mathrm{x} 100 \%
$$

Kemudian hasil pengolahan data dalam prosentase diinterpretasikan menggunakan data kuantitatif dalam bentuk prosentase. Pengelompokan 76-100\% : upaya baik, 56-75\% : upaya cukup $\leq 55 \%$ : upaya kurang.

\section{HASIL}

\section{Data Umum}

a. Karakteristik partisipan berdasarkan usia.

Berdasarkan gambar 4.1 dapat diketahui bahwa 53\% partisipan berusia 21-30 tahun (8 partisipan).

b. Karakteristik partisipan berdasarkan usia pada saat menikah

Berdasarkan gambar 4,2 diketahui bahwa 62\% partisipan menikah saat usia 21-30 tahun (10 partisipan).

c. Karakteristik partisipan berdasarkan usia kehamilan

Berdasartan gambar 4.3 diketahui bahwa 47\% (7 partisipan) usia kehamilan partisipan 29-36 minggu.

d. Karakteristik partisipan berdasarkan pendidikan

Berdasarkan gambar 4.4 diketahui bahwa $67 \%$ pendidikan terakhir partisipan ialah SMA/Sederajat (10 partisipan).

e. Karakteristik partisipan berdasarkan pekerjaan

Berdasarkan gambar 4.5 menunjukkan pekerjaan partisipan ialah IRT dengan presentasi sebanyak $80 \%$ (12 partisipan).

f. Karakteristik partisipan berdasarkan penghasilan

Berdasarkan gambar 4.6 diketahui $80 \%$ partisipan berpenghasilan 1-2 juta/bulan (12 partisipan).

70 Copyright @ 2019, JKM, p-ISSN 2088-6098, e-ISSN 2550-0538 
g. Karakteristik partisipan berdasarkan riwayat kehamilan.

Berdasarkan gambar diketahui 53\% riwayat kehamilan partisipan merupakan kehamilan pertama (8 partisipan).

h. Karakteristik partisipan berdasarkan riwayat penyakit

Berdasarkan gambar 4.8 diketahui $86 \%$ partisipan tidak memiliki riwayat penyakit (13).

i. Karakteristik partisipan berdasarkan lingkungan tempat tinggal

Berdasarkan gambar 4.9 diketahui bahwa 100\% partisipan tinggal di lingkungan yang bersih (15 partisipan).

\section{Data Khusus}

Upaya ibu hamil dalam mencegah bayi berat lahir rendah diwilayah UPTD Kesehatan Kecamatan Sukorejo.Berdasarkan tabel 4.1 diketahui bahwa upaya ibu hamil dalam mencegah bayi berat lahir rendah diwilayah UPTD Kesehatan Kecamatan Sukorejo dikategorikan baik dengan prosentase $73,3 \%$, dan yang menunjukkan cukup dengan prosentase $26,7 \%$.

Upaya Ibu dalam Mencegah BBLR Sesuai dengan Indikator di Wilayah UPTD Kesehatan Keamatan Sukorejo Kota Blitar.Berdasarkan tabel 4.2 diketahui upaya ibu hamil dalam mencegah bayi berat lahir rendah diwilayah UPTD Kesehatan Kecamatan Sukorejo, prosentase tertinggi pada upaya ibu menghindari kebiasaan buruk dalam kategori baik dengan prosentase $100 \%$, upaya ibu melakukan perawatan pranikah dalam kategori baik dengan prosentase $80 \%$, sedangkan prosentase terendah pada upaya ibu untuk mengikuti penyuluhan kesehatan dalam kategori kurang dengan prosentase $87 \%$.

\section{PEMBAHASAN}

Hasil penelitian yang dapat diketahui bahwa upaya ibu hamil dalam mencegah bayi berat lahir rendah diwilayah UPTD Kesehatan Kecamatan Sukorejo dikategorikan baik dengan prosentase $73,3 \%$, dan yang menunjukkan cukup dengan prosentase $26,7 \%$.

Upaya ibu hamil dalam mengikuti penyuluhan kesehatan tentang kehamilan termasuk dalam kategori kurang dengan prosentase $87 \%$. Berdasarkan hasil penelitian terdapat $60 \%$ ( 9 partisipan) ibu hamil tidak pernah mengikuti penyuluhan kesehatan di tempat pelayanan 
kesehatan dengan alasan tidak memiliki waktu atau tidak ada informasi tentang penyuluhan kesehatan ibu hamil. Menurut teori, penyuluhan kesehatan kehamilan, merupakan sarana untuk belajar bersama yang dapat dimanfaatkan ibu hamil, dalam bentuk tatap muka dalam kelompok yang bertujuan untuk meningkatkan pengetahuan dan ketrampilan ibu-ibu mengenai kehamilan, perawatan kehamilan, persalinan, perawatan nifas, perawatan bayi baru lahir, mitos, dan penyakit menular (Depkes RI, 2009). Menurut peneliti seharusnya partisipan bisa menyempatkan waktu untuk mengikuti penyuluhan kesehatan tentang kehamilan dan mencari informasi di tempat pelayanan kesehatan karena kegiatan tersebut dapat meningkatan pengetahuan dan ketrampilan ibu mengenai kehamilan.

Upaya ibu hamil dalam melakukan perawatan kesehatan pranikah (imunisasi TT) termasuk dalam kategori baik dengan prosentase $80 \%$. Berdasarkan hasil penelitian terdapat 80\% (12 partisipan) ibu hamil melakukan imunisasi TT sesuai jadwal. Terdapat $20 \%$ yang tidak melakukan imunisasi TT dengan alasan merasa tidak perlu dilakukan imunisasi. Menurut teori imunisasi TT diberikan untuk mencegah terjadinya tetanus neonatorum (tetanus pada bayi) (Mayasari, 2018). Menurut peneliti kesadaran masyarakat dalam melakukan imunisasi TT sebelum menikah sudah tinggi, meskipun ada beberapa yang masih perlu diberikan sosialisasi tentang pentingnya imunisasi TT sebelum menikah.

Upaya ibu hamil dalam mempertahankan status gizi termasuk dalam kategori baik dengan prosentase $60 \%$. Berdasarkan hasil penelitian terdapat $13,3 \%$ jarang makan teratur dengan alasan mual tidak mempunyai nafsu makan. Menurut teori pola makan yang baik selama kehamilan dapat membantu tubuh mengatasi permintaan khusus karena hamil, serta memiliki pengaruh positif pada kesehatan bayi untuk menyusui dan mengasuh anak (Hannah Hulme Hunter, NTC Book Of Safe Foods dalam Pujiastuti, 2014). Menurut peneliti kesadaran partisipan dalam menerapkan makan teratur sudah baik, jika masih terasa mual sebaiknya ibu mengganti menu makan jangan sampai tidak makan sama sekali.

Upaya ibu dalam menghindari kebiasaan buruk termasuk dalam kategori baik dengan prosentase $100 \%$. Berdasarkan hasil penelitian $100 \%$ tidak pernah mengonsumsi minuman beralkohol, $100 \%$ tidak pernah merokok, $80 \%$ ibu hamil tidak pernah mengonsumsi minuman berkafein. Menurut teori minuman berkafein seperti kopi dan teh jika dikonsumsi secara berlebihan akan membahayakan bagi ibu hamil maupun janinnya. Ibu hamil dapat mengalami darah tinggi, sedangkan bayi akan beresiko lahir premature, berat kurang, bahkan keguguran 
(Agustina, 2018). Menurut peneliti kebiasaan buruk saat hamil harus dihindari karena dapat membahayakan janin. Ibu hamil mungkin tidak mengonsumsi rokok namun ibu juga harus menghindari asap rokok karena keduanya sama-sama berbahaya, selain itu ibu juga harus mengurangi konsumsi minuman berkafein.

Upaya ibu hamil dalam menjaga pola aktivitas termasuk dalam kategori baik dengan prosentase $47 \%$. Berdasarkan hasil penelitian $26,7 \%$ partisipan jarang istirahat pada siang hari, dan $13,3 \%$ partisipan tidak pernah istirahat pada siang hari dengan alasan bekerja pada siang hari, $40 \%$ ibu tidak pernah mengurangi aktivitas selama hamil dengan alasan harus bekerja dan mengurus rumah. Menurut teori istirahat yang cukup adalah syarat, yang tidak dapat ditawar bagi ibu hamil. Dampaknya akan sangat berbahaya untuk seorang ibu hamil yang terlalu banyak beraktifitas dan terlalu lelah, akan sangat berbahaya untuk seorang ibu hamil yang terlalu banyak beraktifitas dan terlalu lelah (Pujiastuti, 2014). Menurut peneliti selama hamil ibu harus cukup istirahat, kontrol aktivitas selama kehamilan, jangan sampai kelelahan karena dapat mengakibatkan kehamilannya terganggu.

Upaya ibu hamil melakukan ANC dalam kategori baik dengan prosentase $67 \%$. Berdasarkan penelitian $73 \%$ selalu melakukan ANC pada trimester II, 20\% tidak pernah melakukan ANC dengan alasan sibuk, tidak ada waktu. Menurut teori sering mengontrol kondisi kehamilan, maka dapat mengetahui tentang perkembangan kehamilan. Selain untuk memastikan bagaimana keadaan bayi dalam kandungan sedini mungkin. Asam Folat diperlukan untuk mencegah risiko cacat saat bayi lahir, misalnya cacat tabung saraf (Pujiastuti, 2014). Menurut peneliti seharusnya partisipan memiliki kesadaran yang lebih untuk memeriksakan kehamilan secara rutin, untuk mengetahui perkembangan janin dan keadaan ibu, selain itu bagi ibu yang belum teratur dalam mengonsumsi tablet Fe harus diberikan pemahaman pentingnya rutin mengonsumsi tablet Fe.

\section{KESIMPULAN}

Dari hasil yang didapat dapat diseimpulkan sebagai berikut:

1. Upaya ibu hamil dalam mencegah bayi berat lahir rendah diwilayah UPTD Kesehatan Kecamatan Sukorejo Kota Blitar sebagian besar termasuk dalam kategori baik dengan prosentase $73.3 \%$.

73 Copyright @ 2019, JKM, p-ISSN 2088-6098, e-ISSN 2550-0538 
2. Prosentase terbanyak upaya ibu hamil dalam mencegah bayi berat lahir rendah adalah dengan menghindari kebiasaan buruk ditunjukkan dengan prosentase 100\%, upaya ibu dalam melakukan perawatan pranikah ditunjukkan dengan prosentase $80 \%$, upaya ibu dalam melakukan ANC dtunjukkan dengan prosentase $67 \%$, dan upaya ibu dalam memenuhi status gizi ditunjukkan dengan prosentase $60 \%$.

3. Prosentase terkecil upaya ibu hamil dalam mencegah bayi berat lahir rendah adalah upaya ibu dalam mengurangi aktivitas selama hamil ditunjukkan dengan prosentase $27 \%$ ibu tidak pernah mengurangi aktivitas, ibu tidak mengurangi aktivitas dengan alasan bekerja, upaya ibu dalam memanfatkan pelayanan kesehatan dan mengikuti penyuluhan kesehatan sangat kurang ditunjukkan dengan hanya 7\% ibu yang selalu datang untuk mengikuti penyuluhan kesehatan, ibu yang tidak mengikuti penyuluhan kesehatan yang diadakan di tempat pelayanan kesehatan ditunjukkan dengan prosentase $87 \%$ dengan alasan tidak memiliki waktu.

\section{SARAN}

1. Bagi Ibu Hamil

Ibu hamil lebih memperhatikan aktivitas dan kebiasaan sehari-hari, serta menyadari pentingnya mengikuti penyuluhan kesehatan untuk meningkatkan pengetahuan dan ketrampilan ibu tentang kehamilan.

2. Bagi Institusi Pelayanan Kesehatan.

Institusi pelayanan kesehatan memberikan perhatian dalam pencegahan BBLR dan mengadakan penyuluhan pada keluarga atau ibu hamil tentang pencegahan BBLR.

3. Bagi Institusi Pendidikan

Institusi pendidikan bahan masukan informasi pengetahuan tentang perawatan antenatal untuk mencegah BBLR. 


\section{DAFTAR PUSTAKA}

Agustina, Fenita. 2018. Kebiasaan Buruk yang Wajib Dihindari oleh Ibu Hamil. (http://ibudanmama.com/kehamilan/ensiklopedia-kehamilan/kebiasaan-buruk-yangwajib-dihindari-oleh-ibu-hamil/, diakses pada 03 Desember 2018)

Badan Pusat Statistik. 2018. Berat Badan Lahir Rendah, BBLR Dirujuk, dan Bergizi Buruk Menurut Kecamatan $\quad$ Kota $\quad$ Blitar 2016. (https://blitarkota.bps.go.id/statictable/2017/10/22/665/7-7-1-jumlah-bayi-lahir-bayiberat-badan-lahir-rendah-bblr-bblr-dirujuk-dan-bergizi-buruk-menurut-kecamatan-dikota-blitar-2016.html, diakses pada 24 September 2018)

Departemen Kesehatan RI. 2009. Pedoman Kelas Ibu Hamil. Jakarta: Depkes RI

Departemen Kesehatan RI. 2015. Survei Demografi dan Kesehatan. Jakarta: Depkes RI

Irham. 2014. Prevalensi Bayi Berat Lahir Rendah. (https://www.scribd.com/doc/239169340/Prevalensi-Bayi-Berat-Lahir-Rendah, diakses pada 16 November 2018)

Mayasari, K. 2018. Imunisasi Wajib Sebelum Menikah. (https://www.klikdokter.com/infosehat/read/3538937/5-imunisasi-wajib-sebelum-menikah, diakses pada 03 Desember 2018)

Permenkes No. 97 Pasal 13 ayat 1 Tahun 2014 tentang Pelayanan Kesehatan Kehamilan Pujiastuti, Ana. 2014. Artikel Konsep Kehamilan Sehat: Upaya Mencetak Generasi Cerdas Yeyeh, Ai dkk. 2012. Asuhan Neonatus Bayi dan Anak Balita. Jakarta: TIM 